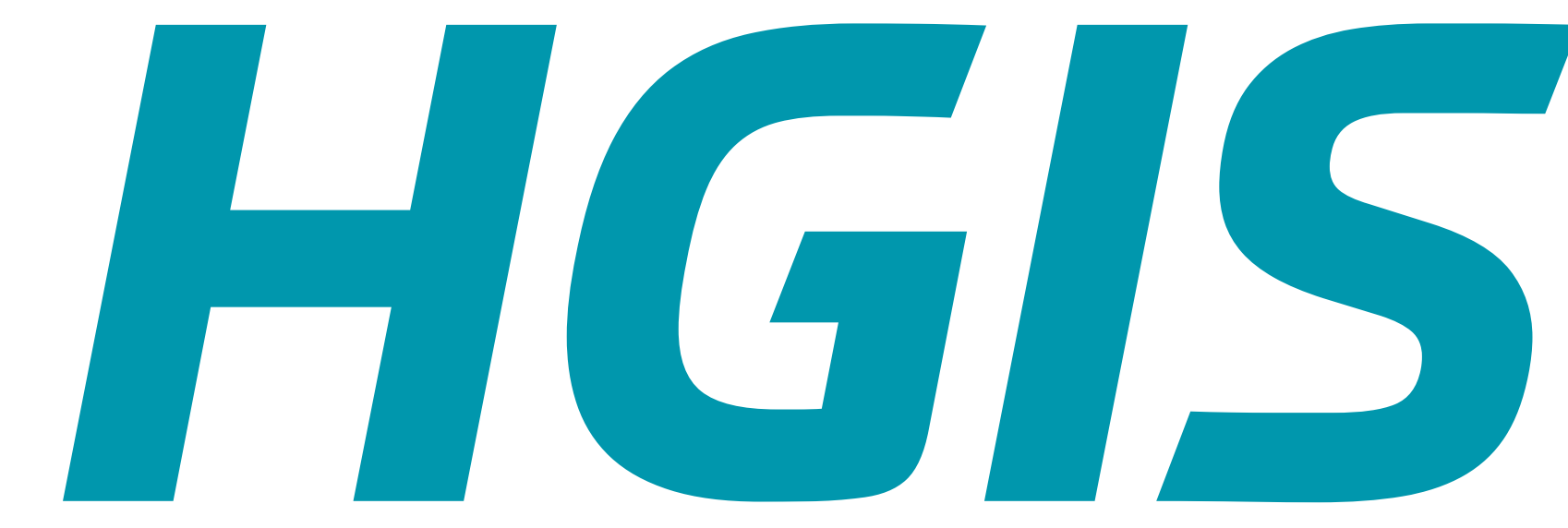

Hospital Geral de Itapecerica da Serra

\title{
PROCESSO DE MELHORIA NA SISTEMÁTICA DE AVALIAÇÕES INTERNAS DE UM HOSPITAL PÚBLICO DA GRANDE SÃO PAULO
}

\section{Lisiane Valdez Gaspary, Gisele de Oliveira Morgado, Adriana Pires dos Santos}

\section{Introdução}

As avaliações internas (Al) permitem o monitoramento dos padrões de qualidade, obtendo evidências por meio de avaliações objetivas que determinam a extensão na qual os requisitos são atendidos, para execução de ações preventivas e corretivas nos serviços, com 0 objetivo de evitar a deterioração do sistema.

\section{Objetivo}

Descrever a experiência de um hospital público da grande São Paulo no planejamento das suas avaliações internas.

\section{Metodologia}

Desde 2005, o Hospital Geral de Itapecerica da Serra (HGIS) possui 0 Grupo de Avaliadores Internos (GAl) com a finalidade de realizar Al para a manutenção e desenvolvimento do Sistema de Gestão da Qualidade no HGIS. Em 2011 foi incorporada a Metodologia Rastreadora nas Al e aumentada a frequência em que as mesmas eram realizadas. Já em 2012 foi elaborado o primeiro Plano de Avaliação Interna para planejar as avaliações a serem realizadas durante 0 ano, contemplando também composição do grupo, perfil do avaliador, competências, formação, responsabilidades, escopo das avaliações internas, instrumentos e relatórios. A partir de 2013 as reuniões passaram a ser ordinárias, com treinamentos focados nas observações de conformidades das Al, análise dos instrumentos de auditoria, alinhamento dos conceitos e posteriormente discussão dos achados (consenso). Em 2014 foi elaborado e aprovado o Regimento Interno do GAl. Neste período, instrumentos específicos para cada avaliação foram elaborados, contemplando roteiros estruturados que incluem perguntas a colaboradores, pacientes/acompanhantes e observações in loco (prontuário, infraestrutura entre outros).

\section{Resultados}

A média anual de conformidades das Al do hospital foi de 93,6\% em 2014 para 94,1\% em 2018. São realizadas em torno de $09 \mathrm{Al}$ anualmente, com foco em sistemas (controle de infecção, medicamentos, prontuários etc.), além das avaliações externas. No total cerca de 36 serviços são avaliados. As avaliações internas tiveram impacto na manutenção da melhoria contínua, resultando na acreditação e reacreditação pela Organização Nacional de Acreditação (ONA) em 2009/2012/2015/2018 e Joint Commission International(JCI) em 2012/2015/2018.

\section{Conclusão}

Um GAl ativo permite um movimento contínuo e ascendente de melhoria com foco no cliente, na visão sistêmica e na melhoria dos processos de forma segura e de qualidade.

Fotos da reunião do grupo de Avaliadores Internos
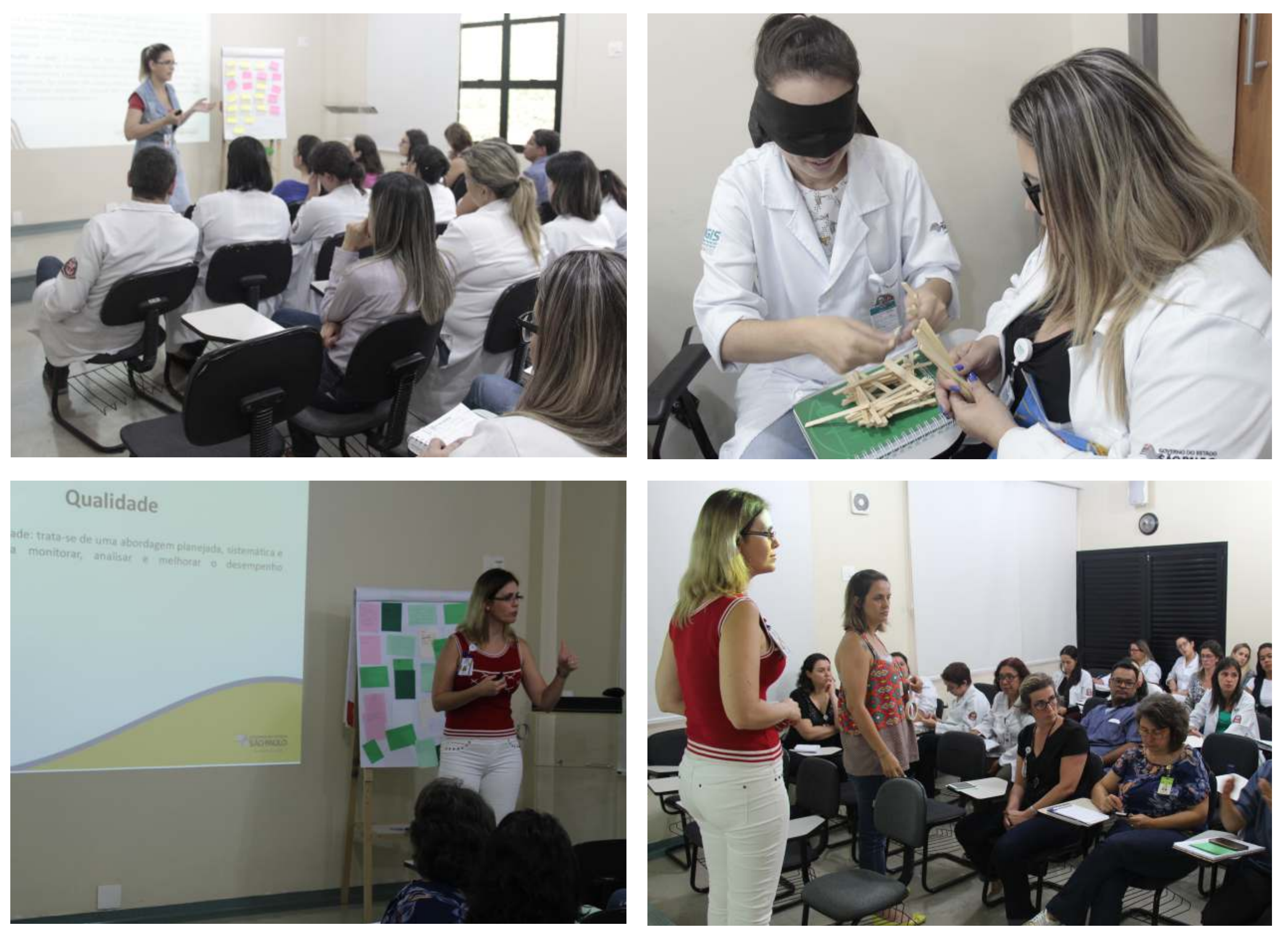
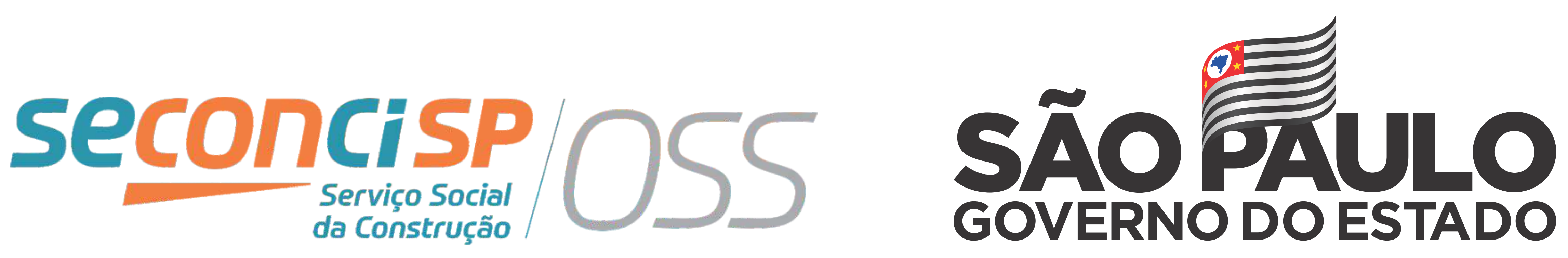